\title{
Arsenic and cadmium are contaminants of concern
}

A t least $5 \%$ of Canadians of all ages have been exposed to arsenic and $5 \%$ of Canadians 40 years of age and older have been exposed to cadmium at levels that exceed government safety standards, according to an analysis of human biomonitoring data collected in Canada from 2007 to 2011 in Toxicology Letters.

The data "are not overly alarming," says Lesa Aylward, principal at Summit Toxicology in Falls Church, Virginia, a consulting company that does chemical

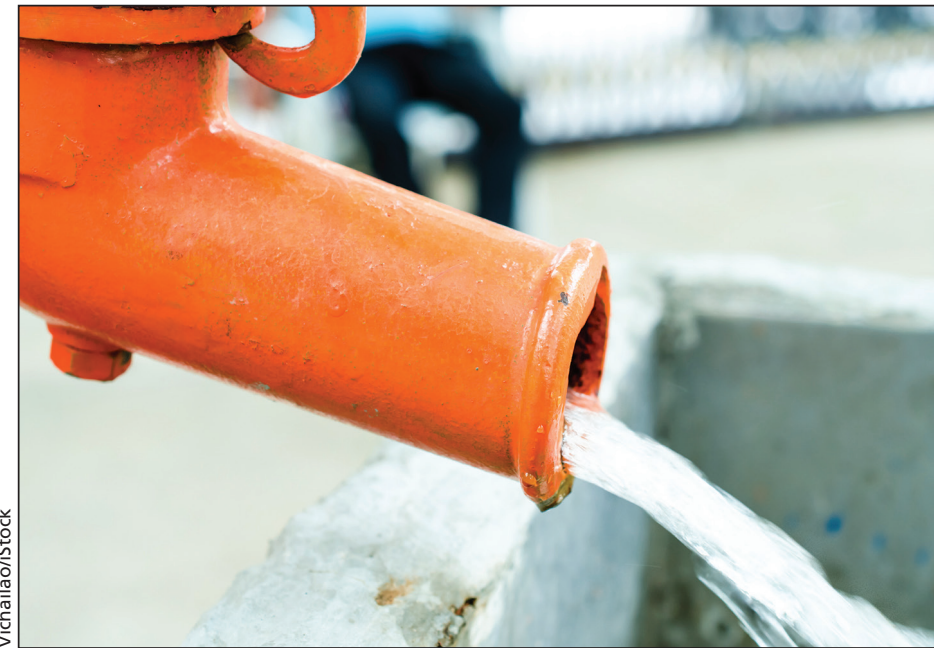

There are pockets of high exposure to arsenic in water in some areas of Manitoba. risk assessment on a contract basis for Health Canada, and a coauthor of the published analysis. However, "arsenic is one of the chemicals that shows up [in the data] at levels we're uncomfortable with." And for cadmium, "the exposure is at a level we would not want to see go any higher." The higher cadmium levels were found in Canadians age 40 and up.

Another cycle of testing has been completed since this analysis, and the latest data, collected 2012-13, show that levels of arsenic and cadmium have not changed significantly, according to Health Canada.

The good news is that a long list of other contaminants - more than 90 environmental chemicals in each of two "cycles" of testing between 2007 and 2011 - were not at hazardous levels in any of those tested. Blood and urine samples were collected from approximately 5600-6400 Canadians aged 3-79 years at 16 sites across Canada as part of the Canadian Health Measures Survey conducted by Statistics Canada, in collaboration with Health Canada and the Public Health Agency of Canada.

Aylward's analysis calculated how test results compare with Health Canada's tolerable daily intake (TDI) for arsenic and the US Environmental Protection Agency's reference dose for cadmium. Arsenic levels exceeded the TDI for the 95th percentile of those tested. And the 95th percentile of people over 40 tested for cadmium - both smokers and non-smokers exceeded the US reference dose.

Aylward points out that government levels are conservative: Health Canada's arsenic TDI is three times lower than the "no-effect" level based on studies of human toxicity, and the US cadmium reference level is 10 times lower.

"We're not seeing a significant number of people in the Canadian population who are routinely exceeding that no-effect level of exposure" to arsenic, said Aylward. She said clinical toxic effects such as hyperpigmentation and keratosis would be expected rarely in the population.

The concern is with pockets of high exposure, such as some areas of Manitoba. Dr. Susan Roberecki, Manitoba's medical officer of health, said that after new standards for drinking water were implemented in that province in 2012, testing found that a few public water systems exceeded standards for arsenic.

Though most water systems are now within standards, "there may be people who haven't tested their wells," says Roberecki. Testing private wells is the responsibility of the land owner, although the province provides advice through fact sheets on its website and media advisories.

Aylward points out that federal biomonitoring is for arsenic metabolites DMA and MMA, which do not directly indicate exposure. As well, testing indicates only short-term levels, as arsenic is rapidly metabolized.

By contrast, urine levels of cadmium are a direct indicator of long-term exposure and its toxic effect on the kidney. Cadmium levels are high among smokers, because tobacco leaves take up cadmium from the soil.

The biomonitoring data show slightly higher levels in seniors, as cadmium accumulates in the body over time. Aylward says these small increases "make a difference; they are not negligible." But she says levels seen are still mainly safe. "We're not even approaching the no-effect level" and far below the level for effects on the kidney.

Roberecki points out that levels of these contaminants in air, soil, food and water are heavily regulated under federal and provincial laws. In Manitoba, for example, air contaminants are monitored at four locations, new industrial plants must meet emission levels under licensing requirements and even potable water for agriculture is covered under the Dairy Act. "There's always more that can be done," she said. "The biomonitoring data is so valuable because it provides a reference level" for local testing. - Carolyn Brown, Ottawa, Ont.

CMAJ 2016. DOI:10.1503/cmaj.109-5173 